\title{
Medical Waste Management in China: A Case Study of Xinxiang
}

\author{
Li Nie',2, Zhong Qiao', Huan $\mathrm{Wu}^{2}$ \\ ${ }^{1}$ China Agricultural University, Beijing, China \\ ${ }^{2}$ Xinxiang Medical University, Xinxiang, China \\ Email: nielily0907@163.com
}

Received 2 April 2014; revised 28 April 2014; accepted 12 May 2014

Copyright (C) 2014 by authors and Scientific Research Publishing Inc.

This work is licensed under the Creative Commons Attribution International License (CC BY). http://creativecommons.org/licenses/by/4.0/

c) (i) Open Access

\begin{abstract}
Due to medical waste's infection and hazard, it can cause potential environmental and public health risks, so medical waste management is of great importance especially in developing countries. The objective of the study was to analyze and assess current status of medical waste management in the light of semi-structured interview in medical institutions and the medical waste disposal centre. As a medium-sized city of China and its respective nature, Xinxiang was selected as the case study. In order to significantly improve eco-efficiency of medical waste management (MWM) and minimize the environmental risks, this paper identified key factors determining the implementation of MWM on the basis of the local realities and situations of medical waste, and then an integrated MWM system was developed. Such the regulations should be improved; MWM database platform should be strengthened; unified coordination ability of the MWM should be developed; and a suitable rural recycling network should be set up.
\end{abstract}

\section{Keywords}

Medical Waste Management, Integrated System, Medical Institutions, Medical Waste Disposal Center, Regulations

\section{Introduction}

Medical waste refers to hazardous waste materials generated by healthcare activities, including a board range of materials, from used needles and syringes to soiled dressing, body parts, diagnostic samples, blood, chemicals pharmaceuticals, medical devices and radioactivity materials (WHO 2005) [1]. Approximately 15\% - 25\% (by weigh) of medical waste is considered infectious [2]. Its potential environmental hazards and public health risks have attracted the attention of the world. There were 5.22 million people every year in the world, including 4 
million children, who died from the diseases caused by the exposure of the medical waste, so effective waste management becomes more and more important than before. With the rapid development of economy in China, from 2003 to 2012, the number of the national health agencies increased three times from 305,000 to 961,830 within 10 years, and at the same time medical waste also increased rapidly. In order to strengthen the safety of the MWM and prevent the spread of diseases, "Regulations on the Administration of Medical Waste" in 2003 and "Hospital Infection Management Method" in 2006 were successively issued in China, which gave some regulations about segregation, collection, storage, transportation, disposal and supervision etc.

Many studies have focused on medical waste in developing countries such as Malaysia [3], Sudan (2013) [4] and Ghana [5]. China, as the biggest developing country, has carried on the related research recently, and some medical waste management suggestions were given by analyzing the questionnaire such as Nanjing city [6], Shandong province [7] and Gansu province [8]. The hospital was the object in these studies; however, few have paid enough attention on taking the medical waste of segregation, collection, transportation, disposal, management, supervision as a whole system except one study for Shenyang [9]. The different management bodies are connected in processing medical waste; moreover, the macro management system of China is unique, so it is greatly significant that each step of the MWM is taken as a comprehensive system.

This study chose the city of medium development level as the subject of study-Xinxiang which could represent the average level of the MWM. Furthermore, Xinxiang was identified as the one of six UN models of medical waste disposal facilities in China and it is the only city located in Henan province. At the same time, the way of system research can be used on the basis of whole MWM which is a system with various departments such as hospitals, solid waste disposal centre, health bureau, urban management bureau and waste disposal center. We firstly introduce the study area and method, and then provide a detail description on how MWM is going on in Xinxiang. We focus on identifying the main problems on MWM and then raise appropriate suggestions, which can also be shared by other cities in China or cities in other developing countries that face the same challenges.

\section{Methods}

\subsection{The Study Area}

Xinxiang, which locates in the north of Henan province, is an important part of the central plains economic zone and its area is 8249 square kilometers. In 2012, it had a population of 5.7 million, and the total GDP was 161.9 billion RMB (approximately 26.42208 USD) which had a growing at $11.4 \%$ a year and was the fifth in Henan province; there were 729 healthcare institutions at the end of 2012 including 247 hospitals and health-centers, 12 maternity and child care institutions and 13 epidemic prevention and control institutions. There were 26,900 sickbeds including 25,400 sickbeds in hospitals and health-centers. We can see $94.42 \%$ beds were in hospitals and health-centers which produced a lot of medical wastes. The rate of preventive health supervision reached above $85 \%$ which was in a leading position in the province.

\subsection{Data and Methodology}

In order to understand the situation information of MWM, the data was derived from the government websites, unpublished documents and published paper; the method is semi-structured interview which is flexibility and freedom. This method can give full enthusiasm, flexibility and creativity to the interview. In third-tier cities of China the MWM is at the early stage, which is not suitable for quantitative analysis, so qualitative approach is appropriate. The interviews and questions were designed on the base of the nation MWM regulations (2003), the World Health Organization's questionnaire [10] (WHO, 1999).

In addition, responses were obtained from 20 officials and managers, 20 doctors and nurses, and 30 workers in hospitals and medical waste disposal center. We found workers were more positive and enthusiastic to interview than the others, so they had a high response rate of $93.33 \%$. The others had a response rate of $82 \%$.

\section{Main Managements}

\subsection{The MWM Goal}

The management goal is realized by harmlessness, reduction and recycle of medical waste, and the management 
should fully cover small-scale clinics and hospitals. The goal can be subdivided into three segments, such as medical institutions, medical waste disposal and collection rate of medical waste in Figure 1, where we can see that each segment has its own requirement.

\subsection{The Management and Supervision Framework of Medical Waste}

The duties of various related departments have been clear in the process of medical waste, which are presented in Figure 2.

The Health of Bureau mainly focus on supervising and administering disease prevention in whole process of segregation, collection, transportation, storage and disposal of the medical waste, and is responsible for the preparation of MWM of contingency plans; the Environmental Protection Bureau mainly focuses on supervising and administering prevention and control of environmental pollution; the Urban Management Bureau should supervise and administer medical wastes safely. Medical waste disposal centre (Yuri International Environmental Science and Technology Company, in Xinxiang) is responsible for the timely collection, transportation and safe disposal of medical wastes and preparation of medical waste disposal according to the emergency response plans.
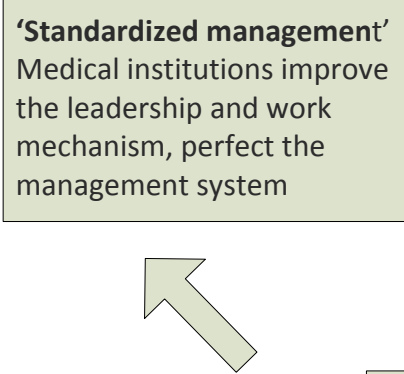

'Increase the rate of collection and disposal' The rate should be $100 \%$ in medical institutions of town, country and city

Figure 1. The MWM goal of Xinxiang.

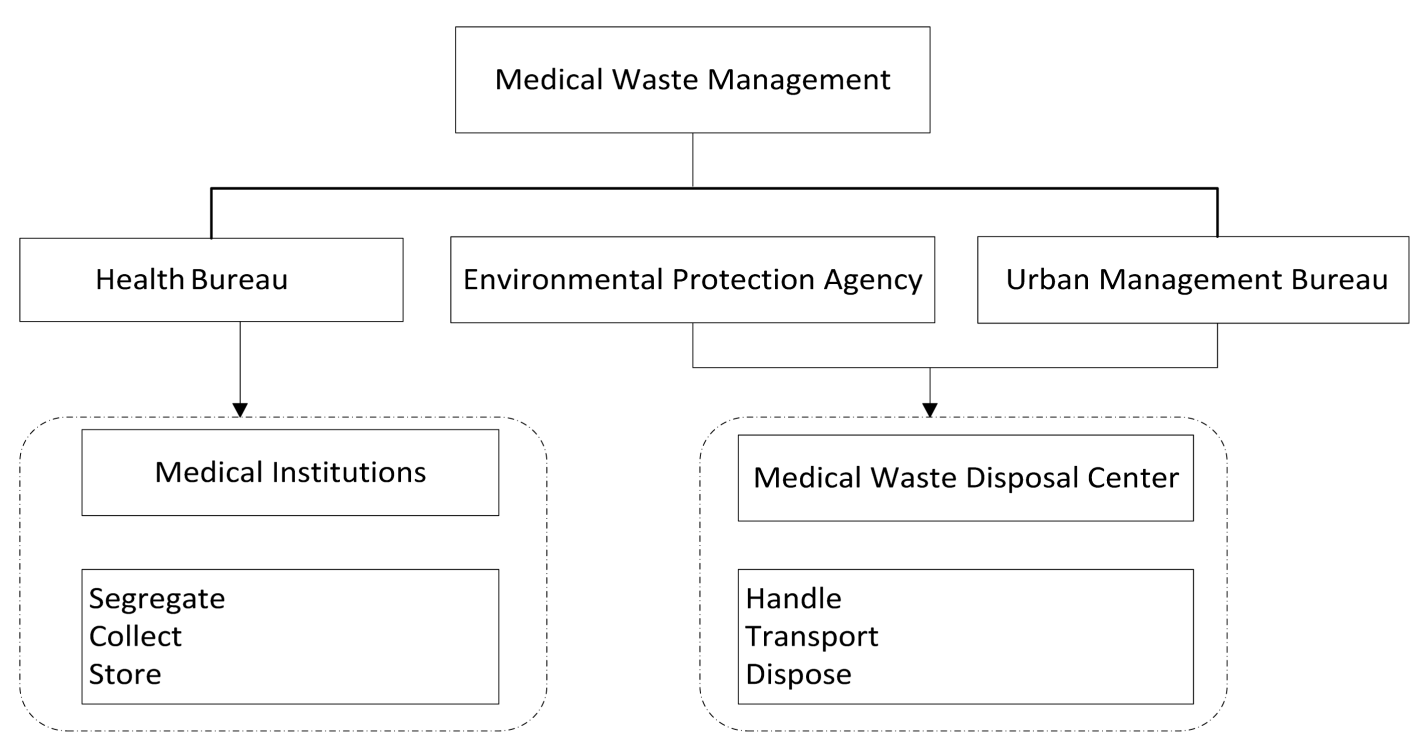

Figure 2. MWM framework in Xinxiang. 


\subsection{The Main Administering Measures on Medical Waste}

In order to improve efficiency, special administration departments of medical waste have been established, which were medical policy department in the Health Bureau and solid waste management central in the Environmental Protection Bureau. In recent years they have developed special policies and regulations except for country's regulation, and carried out a series of inspection to supervise and administer medical wastes, which are listed in Table 1. According to their nature, they can be classified into two types: the local government regulation, the department news. Combined with the Xinxiang practical situation, the local government regulations were made on the base of laws and regulations of China. The department news was mainly measures and administrations of medical waste. We found the numbers of regulations and news was more than that of before, after Xinxiang was identified as the model of medical waste disposal facilities in 2010. The main administering measures were summarized as follows:

In order to ensure implementation of the project, the joint meeting system of Xinxiang MWM were built in January 2011, which could timely solve the problems in the process of implementation of the projects and whose members were the leaders of the Environmental Protection Agency, Health of Bureau, Urban Management Bureau and the Development and Reform Commission. They also were responsible for guidance, supervision and coordination work of medical waste.

Three hospitals were selected as demonstrations of medical waste management. Xinxiang Central Hospital, the First People's Hospital and the Infectious Diseases Hospitals were selected, where some measures were taken, medical staffs and leaders especially were trained to study laws and regulations in the administrative department of health and medical institutions; nearly ten thousand RMB were input in transformation and extension of the temporary storage, updating of transit vehicles, the reconstruction and replacement of disposable medical supplies and standardizing the packages of medical waste and etc.; transit of medical waste was strictly regulated, and each department should strength the registration system, the collection staff of medical waste should keep wastes good-sealed in the transit process; staff of temporary storage should verify the number of medical waste and standardize the day-to-day management.

In order to make medical wastes reducing and harmless, medical wastes were classified according to the catalog of country medical waste classification and the directory lists of medical waste were formulated, which was combined with the hospital situation, such more one-time items and dosage of chlorine disinfectants should be decreased as far as possible.

\subsection{The Medical Waste Generation and Disposal}

In order to concentrate disposal of medical waste, the medical waste disposal center was built in 2008 with a to-

Table 1. Recent regulations and activities with respect to MWM in Xinxiang.

\begin{tabular}{|c|c|c|c|}
\hline Regulations and activities & Issued division & Date & Nature \\
\hline Recycling disposal agreement of disposable plastic (glass), infusion bottle (bag) & HB, EPA & 2013/05/01 & DN \\
\hline Checked the unlicensed clinics & HB & 2013/01/10 & DN \\
\hline Inspected MWM specially & HB & 2012/08/28 & DN \\
\hline Checked the primary health institutions & HB & 2012/03/31 & DN \\
\hline Notice on enforcing the supervision and management of the directions of Xinxiang medical waste & PG & 2011/03/15 & GR \\
\hline Notice on building the joint meeting system of Xinxiang MWM as the demonstration city & PG & $2011 / 01 / 21$ & GR \\
\hline Notice on solution of Xinxiang medical waste comprehensive management & PG & $2011 / 01 / 21$ & GR \\
\hline Regulated medical waste disposal management & HB & 2010/09/29 & DN \\
\hline Notice on clarifying regulatory and strengthening the management of medical waste disposal & PG & $2007 / 12 / 26$ & GR \\
\hline Regulation on the administration of Xinxiang medical waste & PG & 2004/03/18 & GR \\
\hline
\end{tabular}

EPA: the Xinxiang Environmental Protection Agency, HB: the Xinxiang Health Bureau, PG: the Xinxiang People’s Government, GR: the Government Regulations, DN: Department News. 
tal investment of 14.2 million RMB, and was designed to dispose 8 tons medical wastes every day. Dry alkaline disinfection technique was used, which did not generate waste liquid and gas throughout the process and did not pollute the environment. And this technique is suitable for the third-tier cities that garbage is relatively a little. Agreement including 89 hospitals in Xinxiang and more than 300 clinics were signed to manage their medical wastes by the centre, so the weight of the disposed medical waste has increased from 500 tons in 2008 to more than 1000 tons now, so the outflow of medical wastes and risks were decreased.

Xinxiang comprises 4 districts, 2 cities, five counties (including Weibin, Hongqi, Muye and Fengquan district; Weihui, Huixian city; Xinxiang, Huojia, Yuanyang, Yanjin and Fengqiu county), whose 4 districts are located in the downtown and Class II or higher rated medical institutions in these districts have completely collected medical wastes, Class I or higher rated hospitals have completely collected in 6 counties except that Fengqiu county is planning to collect. Figure 3 shows that the medical waste disposal centre locates in Fengquan district and is far from others places.

\section{Challenges and Recommendations}

\subsection{Challenges of MWM}

Although Xinxiang MWM has gained certain achievements, such as the clear responsibilities framework and a certain rate waste collection, there are still some problems.

Firstly, efficient enforcement of medical waste regulations is still a problem. Although the administration duties of relevant departments have been clear, supervision and inspection of the MWM are a few and the response penalties are not executed; some authorities do not pay attention to MWM and think that inspections are not necessary; though medical institutions and medical waste disposal centre have some data, yet there are some problems such as data missing, distortion etch; collection staff lacks training in medical waste.

Secondly, informationization in MWM is low and the awareness of the related staffs needs improving; the relevant contents of medical waste are seldom in the site of the People's Government of Xinxiang, Health of Bureau and Environmental Protection Agency, and there are no specific training tutorial, supervision, inspection and the database. Awareness of staffs is not high, knowledge rate about laws and regulations of the medical workers was only $78.17 \%$ in medical institutions and the other departments in medical waste [11], non-medical people in the medical waste collection, storage, transportation and disposal have a certain proportion, which makes it poor to avoid the risks of medical waste and are fuzzy to the waste management in an emergency, so they need effective information of medical waste.

Thirdly, there are conflicts between medical waste segregation and disposal method, and there is a problem of funds allocation of medical waste. Though segregation of medical waste in the medical institution is fine, but after being shipped to the plant, they are taken together and crushed, compressed and treated, so the segregation becomes no necessary, the staff and time are wasted.

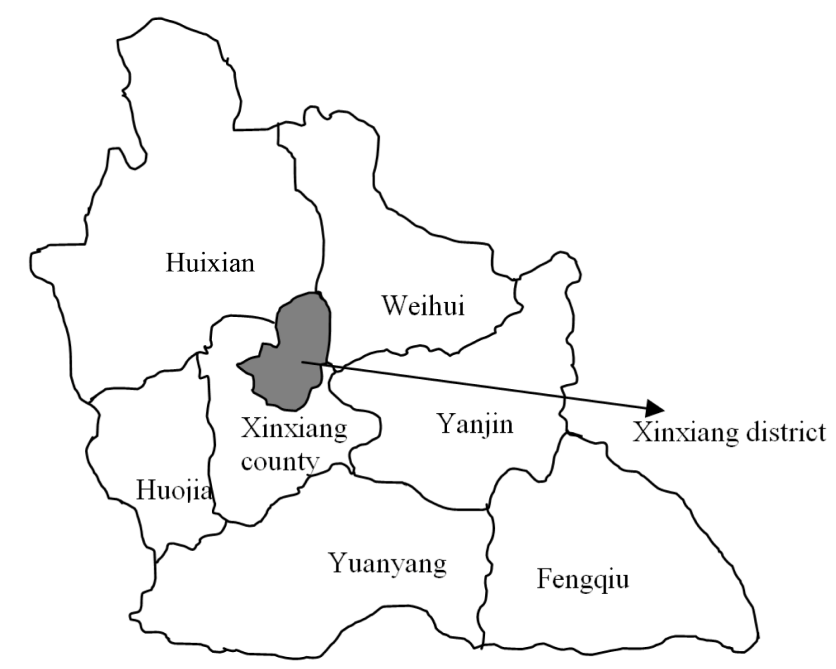

Figure 3. The geography of Xinxiang. 
Medical waste funds are unequal and underfunded. The income of medical waste disposal centre is from the fees which are paid for by medical institutions, and now default fees have not been solved. Medical waste disposal centre think it is not reasonable. Fees cannot be completely gained as that eighty percent of fees can be gained in downtown hospital and sixty percent in county hospital, it can be shown from Figure 4 and Figure 5. At the same time, medical institutions think that they have invested manpower and necessary equipments, such as collection vehicles, the construction of temporary storage, but they can gain little or no medical waste management fee. In addition, medical institutions and medical waste disposal center have no other incomes to deal with medical waste. As a result the investments in the hardware and software of medical waste are poor.

Finally, medical waste collection cost is high in the county and the following towns and medical wastes are not unified recycled in township hospitals and village clinics. From the previous figure we learn that the medical waste disposal center is located in Fengquan district of Xinxiang, which is far from the county seat and the following the medical institutions, so transport costs are high; moreover, the medical wastes are less in these institutions than others, and transport vehicles cannot be filled every time. All of these reduce the enthusiasm of the medical waste disposal center. In addition, the medical wastes are not collected together and a potential risk to human exists in township hospitals and village clinics.

\subsection{Recommendations of MWM}

From the above issues, we can adopt an integrated MWM system like the Figure 6, where four characteristics are presented.

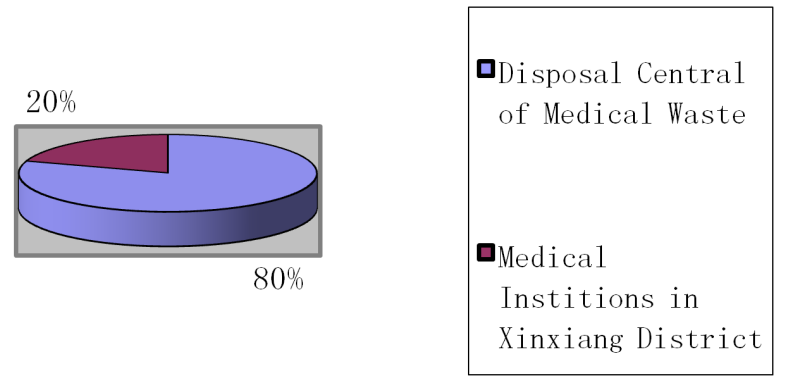

Figure 4. Fees distribution of medical waste.

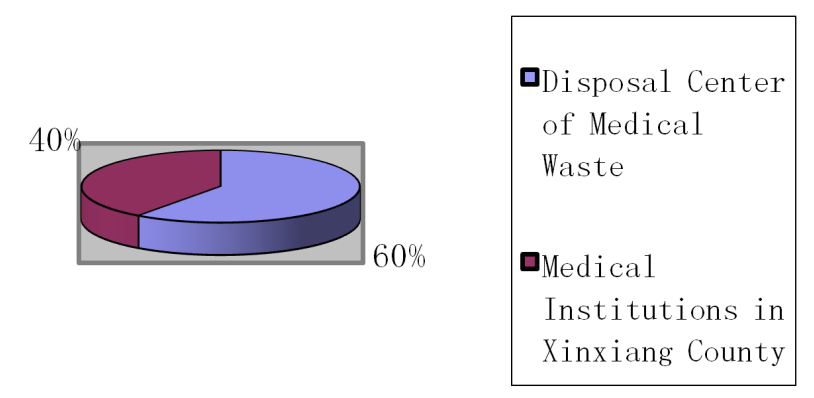

Figure 5. Fees distribution of medical waste.

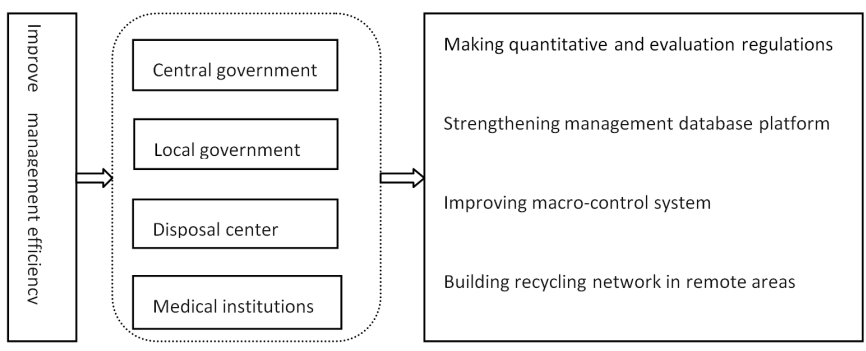

Figure 6. Integrated MWM system of Xinxiang. 
First of all, from the macro level, the MWM regulations should be improved, if we want to strive to build ecological civilization and better homes, as Premier Li promised in his report on government work, we must strengthen the ecological environment protection and determine to finish the important task by using important measures. It looks that Chinese government has realized the importance of environmental protection. On the basis of the MWM regulations in 2003, the central government must make quantitative and indexing rules as soon as possible, define the specific management operation process; the provincial governments should take the overall responsibilities, manage by objectives, strengthen the supervision and guidance, and appraise the performance of the city governments so that local governments can pay attentions and comply with the provisions of the regional development. From the micro level, administrative staffs of Xinxiang should give full play to guide supervision; on the basis of improving detailed indicators of the medical wastes, they should normalize the supervision and inspection work, strengthen them by using the regular inspection and spot check and report the results of inspection in time. In this way we can prove efficiency of management.

Secondly, the MWM database platform should be strengthened to enhance information transparency. Proper training must be carried out for hospital employees to develop awareness of health, safety and environmental issue [12]. So central government should has special medical waste sites, training tutorials, emergency plans and service guide database which will help related units and public to not only identify knowledge popularization of MWM but also to promote information public, transparent, strengthen the supervision by public opinion and enhance the public enthusiasm of conservation environment.

Xinxiang authorities also should set up the digital platform of local MWM, such as network, micro, micro blog, and timely report the status; we should improve the participation mechanisms including government, enterprises and public, and implement a zone defense and improve the efficiency of management.

Thirdly, the macro-control system of medical waste should be improved constantly in order to promote steady and sustainable development. Because medical institutions and medical waste disposal centre did not make effective communication and lacked the unity of macroscopic coordination, so the macro-control should be given full play by relevant municipal agency, such like that the government guides the medical institutions with the corresponding segregation method in order to reduce the waste of resources; rational proportion of guidance of the allocation of funds can be given by referring the big cities, at the same time, because waste disposal is a public welfare project, the government should offer certain support and subsidies to improve the working enthusiasm and effectiveness.

Fourthly, the medical wastes in villages, townships and remote areas should be disposed effectively and suitable recycling network should be set up. Because in the county and town hospital, the transport costs of medical waste are high, so the medical waste temporary storage can be set up to get the medical wastes together for the adjacent regions. The effective way to reduce logistics costs is to realize the reasonable location, the optimal routes and advanced technology. The rate of centralized disposal of medical waste is low or not especial in remote areas, moreover, our regulations do not set uniform standards about "remote areas" and cannot be supervised, and so unified recycling becomes a difficult problem in these areas. National policies and regulations should be clear, medical institutions in remote countries can give their wastes for unified township recycle; at the same time governments should give appropriate subsidies to assist complete recovery.

\section{Conclusion}

In Xinxiang, MWM has developed regulations to ensure appropriate processing medical waste; several challenges still exist, including ineffective enforcement, low information, lack of awareness, a conflict between segregation and disposal method, a problem of fees distribution of medical waste, and high collection cost in the county and the following towns. In order to prompt sustainable development of medical waste, some recommendations are presented based on integrated MWM system. Major initiatives include quantitative and evaluation regulations, macro-control system, a management database platform as well as recycling network in remote areas.

\section{Acknowledgements}

This research was supported by Scientific Research Fund of Xinxiang Medical University (No. 2013QN202). The authors are grateful to relative management bureau in Xinxiang and those anonymous people for their keen cooperation and assistance with this study. 


\section{References}

[1] WHO (2005) Safe Healthcare Waste Management-Policy Paper by the World Health Organization. Waste Management, 25, 568-569.

[2] Shinee, E., Gombojav, E., et al. (2008) Healthcare Waste Management in the Capital City of Mongolia. Waste Management, 28, 435-444.

[3] Ambali, A.R. and Bakar, A.N. (2012) MWM in Malaysia: Policies, Strategies and Issues IEEE Colloquium on Humanities. Science \& Engineering Research, Kota Kinabalu, 3-4 December 2012.

[4] Saad, S.A. (2013) Management of Hospitals Solid Waste in Khartoum State. Environmental Monitoring and Assessment, 185, 8567-8582. http://dx.doi.org/10.1007/s10661-013-3196-1

[5] Abor, P.A. (2013) Managing Healthcare Waste in Ghana: A Comparative Study of Public and Private Hospitals. International Journal of Health Care Quality Assurance, 26, 375-386.

[6] Zhang, Y., Xiao, G., Wang, G.X., et al. (2009) Medical Waste Management in China: A Case Study of Nanjing. Waste Management, 29, 1376-1382. http://dx.doi.org/10.1016/j.wasman.2008.10.023

[7] Xu, L.Z., Wang, X.Z., Zhang, Y.F., et al. (2009) Hospital Medical Waste Management in Shandong Province, China. Waste Management \& Research, 27, 336-342. http://dx.doi.org/10.1177/0734242X09104384

[8] Zhang, H.-J., Zhang, Y.-H., Wang, Y., et al. (2013) Investigation of Medical Waste Management in Gansu Province, China. Waste Management \& Research, 31, 655-659. http://dx.doi.org/10.1177/0734242X13482161

[9] Geng, Y., Ren, W.-X., Xue, B., et al. (2013) Regional Medical Waste Management in China: A Case Study of Shenyang. Material Cycles and Waste Management, 15, 310-320. http://dx.doi.org/10.1007/s10163-013-0118-9

[10] Prüss, A., Giroult, E. and Rushbrook, P., Eds. (1999) Safe Management of Wastes from Health-Care Activities. World Health Organization, Geneva.

[11] Li, T.B., Sheng, L.Y. and Zhou, L. (2012) Medical Staff Medical Waste Related Knowledge Status Survey in Dalian. Public Health Management of China, 28, 517-518.

[12] Mohee, R. (2005) Medical Wastes Characterization in Healthcare Institutions in Mauritius. Waste Management, 25, 575-581. http://dx.doi.org/10.1016/j.wasman.2004.10.003 
Scientific Research Publishing (SCIRP) is one of the largest Open Access journal publishers. It is currently publishing more than 200 open access, online, peer-reviewed journals covering a wide range of academic disciplines. SCIRP serves the worldwide academic communities and contributes to the progress and application of science with its publication.

Other selected journals from SCIRP are listed as below. Submit your manuscript to us via either submit@scirp.org or Online Submission Portal.
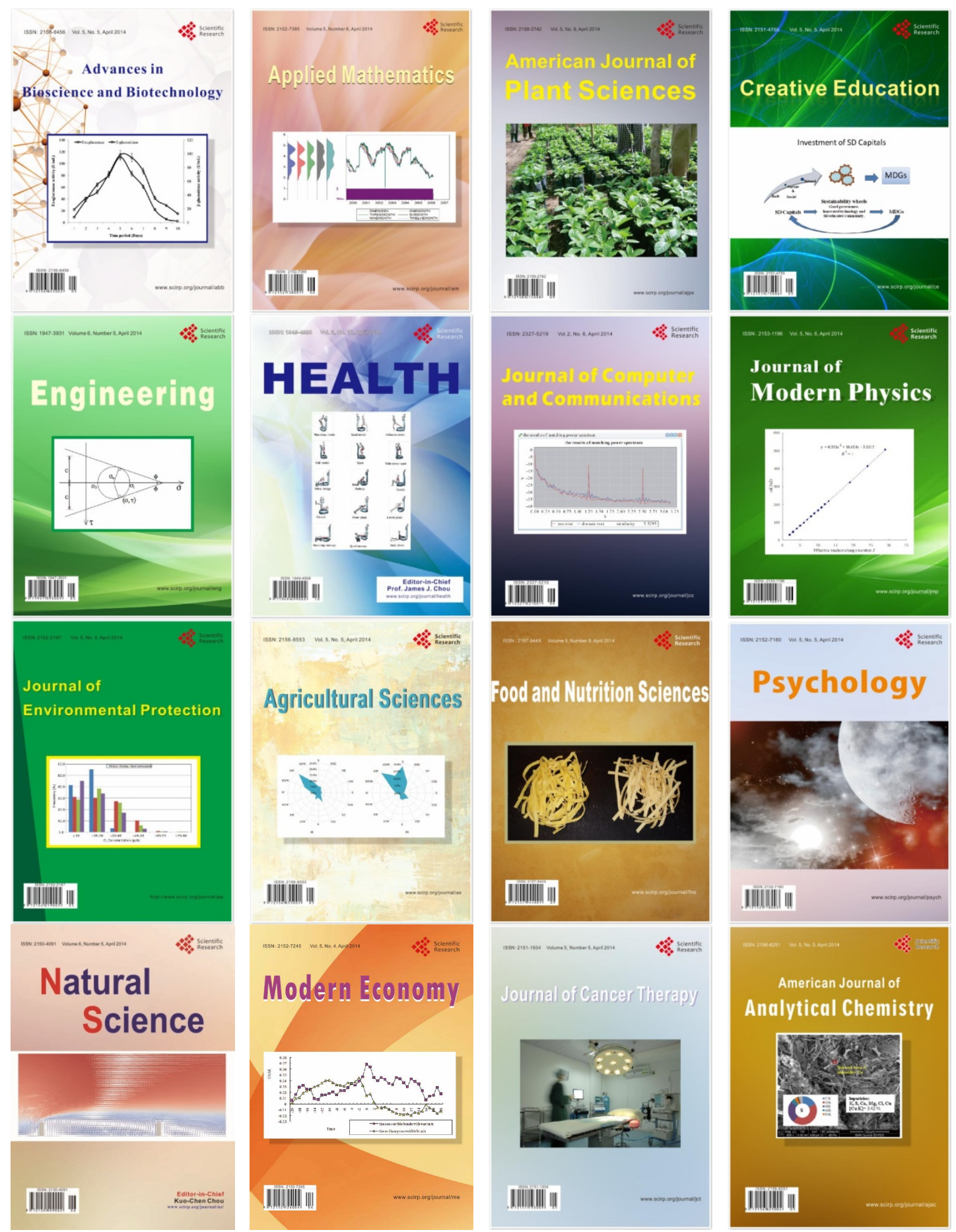